\title{
ERRATUM
}

Zhiguang Xiao · Andrew R. Gardner Maddalena Cross · Estelle M. Maes Roman S. Czeruszewicz · Marco Sola Anthony G. Wedd

\section{Redox thermodynamics of mutant forms of the rubredoxin from Clostridium pasteurianum: identification of a stable $\mathrm{Fe}^{\mathrm{III}}(\mathrm{S}-\mathrm{Cys})_{3}(\mathrm{OH})$ centre in the $\mathrm{C6S}$ mutant}

Published online: 24 August 2001

(C) SBIC 2001

\section{J Biol Inorg Chem (2001) 6:638-649}

In the printed version of the article, Table 2 on p. 641 was scrambled. The correct version of the table is below:

Table 2 Redox thermodynamic data for reduction of $\operatorname{Rd} C p$ proteins at $25^{\circ} \mathrm{C}^{\mathrm{a}}$

\begin{tabular}{|c|c|c|c|c|c|}
\hline \multirow[t]{2}{*}{ Protein } & \multirow[t]{2}{*}{$\mathrm{pH}^{\mathrm{b}}$} & \multirow{2}{*}{$\begin{array}{l}\mathrm{d} E_{\mathrm{p}} / \mathrm{d} t \\
(\mathrm{mV} / \mathrm{K})\end{array}$} & \multicolumn{2}{|c|}{ Contribution to $E^{\circ \prime}(\mathrm{mV})$} & \multirow[t]{2}{*}{$E^{\circ \prime}(\mathrm{mV})$} \\
\hline & & & $\Delta H_{\mathrm{rc}}^{\circ} / F$ & $T \Delta S_{\mathrm{rc}}^{\circ \prime} F$ & \\
\hline \multirow[t]{2}{*}{$\mathrm{rRd} C p$} & $6.0-10.0$ & -0.85 & +170 & -255 & -85 \\
\hline & $6.7^{c}$ & - & +231 & -263 & $-32^{\mathrm{c}}$ \\
\hline \multirow[t]{2}{*}{$\mathrm{C} 6 \mathrm{~S}$} & 8.0 & -1.43 & +300 & -425 & -125 \\
\hline & 10.0 & -0.88 & +90 & -260 & -170 \\
\hline \multirow[t]{2}{*}{ C9S } & 6.0 & -0.66 & -60 & -195 & -255 \\
\hline & 8.0 & -0.82 & -50 & -245 & -295 \\
\hline \multirow[t]{2}{*}{$\mathrm{C} 39 \mathrm{~S}^{\mathrm{d}}$} & 8.0 & -0.63 & +20 & -185 & -165 \\
\hline & 10.0 & -0.58 & -15 & -175 & -190 \\
\hline \multirow[t]{2}{*}{$\mathrm{C} 42 \mathrm{~S}$} & 6.0 & -0.51 & -55 & -150 & -205 \\
\hline & 8.0 & -0.73 & -55 & -220 & -275 \\
\hline \multirow[t]{2}{*}{$\mathrm{C} 9 \mathrm{~S} / \mathrm{C} 42 \mathrm{~S}$} & 8.0 & -0.02 & -470 & -5 & -475 \\
\hline & 10.0 & -0.57 & -370 & -170 & -540 \\
\hline $\mathrm{V8G} / \mathrm{V} 44 \mathrm{G}$ & 8.0 & -0.89 & +305 & -265 & +40 \\
\hline V44A & 8.0 & -0.73 & +205 & -215 & -10 \\
\hline V8I/V44I & 8.0 & -0.93 & +210 & -275 & -65 \\
\hline G10V/G43A & 8.0 & -0.53 & +15 & -160 & -145 \\
\hline $\mathrm{G} 10 \mathrm{~V} / \mathrm{G} 43 \mathrm{~V}$ & 8.0 & -0.59 & +10 & -175 & -165 \\
\hline
\end{tabular}

a Parameters derived by curve fitting of the experimental data as a function of temperature (see Materials and methods section and Figs. 5 and 6 )

${ }^{\mathrm{b}}$ Conditions: $30 \mathrm{mM}$ buffer ( $\mathrm{pH}$ 6.0, Mes; $\mathrm{pH} 8.0$, Tricine; $\mathrm{pH} 10.0$, Caps); $100 \mathrm{mM} \mathrm{NaCl}$

${ }^{\mathrm{c}} \operatorname{Ref}[28] ; 25 \mathrm{mM}$ phosphate; $50 \mathrm{mM} \mathrm{MgCl}_{2}$

${ }^{\mathrm{d}}$ Uncertainties for this protein are large; see Materials and methods section

The online version of the original article can be found at http://dx.doi.org/10.1007/ s007750100241

Z. Xiao $(\bowtie) \cdot$ A.R. Gardner · M. Cross · A.G. Wedd

School of Chemistry, University of Melbourne,

Parkville, Victoria 3010, Australia

E-mail: z.xiao@unimelb.edu.au

M. Sola

Dipartimento di Chemica,

Università di Modena e Reggio Emilia,

Via Campi 183, 41100 Modena, Italy

E.M. Maes · R.S. Czeruszewicz

Department of Chemistry,

University of Houston,

Houston, TX 77204-5641, USA 